\title{
MECHANISM AND SIGNIFICANCE OF THE THYMOL TURBIDITY TEST FOR LIVER DISEASE
}

\author{
By HENRY G. KUNKEL AND CHARLES L. HOAGLAND 1 \\ (From the Hospital of the Rockefeller Institute for Medical Research, New York City)
}

(Received for publication April 7, 1947)

An increase in the amounts of the globulin components of the serum has long been recognized in advanced states of liver disease $(1,2,3)$, although the significance of the alteration has never been defined. It has been the basis of the Takata-Ara, Weltmann and the formol-gel reactions which have been used for many years in the diagnosis of liver disease. The nonspecific nature of these tests is now clear following the demonstration that positive reactions are found in any disease showing marked hyperglobulinemia $(4,5,6)$. More recently, several new serum reactions, which appear to depend on small changes in the proteins of the serum, have been used for demonstrating liver disease. These include the cephalin flocculation, the colloidal gold and the thymol turbidity tests. The cephalin flocculation reaction has been studied in detail by Hanger and his coworkers $(7,8)$ and has been found to be a sensitive index of liver damage. The test may be positive in patients with liver disease who show normal serum protein values according to the usual methods of protein estimation and, conversely, the serum of patients with marked hyperglobulinemia may show negative cephalin flocculation reactions. The exact serum protein constituent that is altered in liver disease and is responsible for a positive cephalin flocculation test has not been clearly established; recent work by Hanger (8) appears to implicate albumin in addition to gamma globulin. The final solution to the problem is hampered by the complexity of the cephalin flocculation reaction, a fact which is also true of the colloidal gold reaction.

The technique of the thymol turbidity test is much simpler, however, and probably consists of a direct precipitation of a protein appearing in liver disease by the addition of a thymol solution. It would seem, therefore, that a study of the mechanism of this reaction and the protein com-

1 Deceased, August 2, 1946. ponent concerned would be more likely to yield clear-cut information regarding at least one of the proteins that appear in the blood stream during diseases of the liver. The present study was an attempt to elucidate the mechanism of the reaction and to define its significance in terms of clinical observations.

\section{MATERIALS AND METHODS}

The sera used in the study of the thymol turbidity reaction were selected from a group of 200 patients with infectious hepatitis and 65 patients with other liver disorders admitted to the Out Patient Department of the Hospital of the Rockefeller Institute.

Technique of performing the thymol turbidity test. The thymol reagent was prepared as described by Maclagan (9). Slight variations of this method produced unsatisfactory results. In alkaline solution thymol is somewhat unstable and turbidity of the reagent often occurs on standing. Exposure to air increases the turbidity of the solution and it was found important to keep the thymol reagent tightly stoppered. As the solution becomes increasingly cloudy, its activity decreases and it is important that only clear or very slightly turbid solutions be used. If properly prepared, the thymol reagent is satisfactory for at least one month. Although the $\mathrm{pH}$ of the thymol reagent was slightly lower than that originally stated by Maclagan, it proved to be satisfactory.

Three ml. of the thymol reagent were added to 0.05 $\mathrm{ml}$. of serum and the degree of turbidity measured in the Coleman Jr. spectrophotometer at $650 \mathrm{~m} \mu$. This represented a 1/60 dilution and corresponded to that originally described by Maclagan. Figure 1 shows the turbidity of sera from cases of liver disease at various dilutions of reagent using saline dilutions as controls. It can be seen that the maximum turbidity was usually obtained at a $1 / 12$ dilution and that differences in certain sera at the lower dilution might not be so marked at the $1 / 60$ dilution. Although the use of lower dilutions has certain apparent advantages, all determinations discussed in this paper were performed at Maclagan's standard $1 / 60$ dilution.

The degree of turbidity was compared with a $\mathrm{BaSO}_{4}$ standard as described in a previous publication (10). This proved to be a satisfactory standard regardless of tube size or type of instrument used. The units of turbidity corresponded to those originally described by Maclagan using visual comparators. 


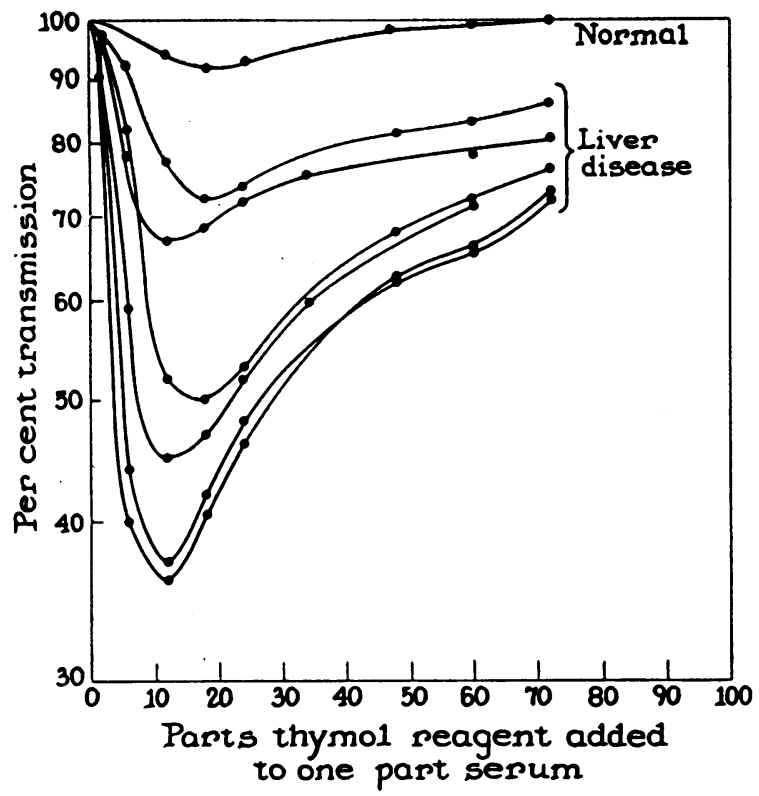

Fig. 1. Turbidity Readings as Measured in the Spectrophotometer at Various Dilutions of Serum WITH THYMOL REAGENT

Estimation of the degree of flocculation of the thymol serum mixture was also carried out in a number of patients. The finding of Neefe (11) that in certain patients, following an attack of infectious hepatitis, the 24-hour flocculation with thymol reagent remained positive for a slightly longer period than the usual thymol turbidity reaction, was confirmed. In general, however, the estimation of flocculation proved to be a less sensitive index than turbidity determinations, and did not furnish quantitative results.

Electrophoretic analyses were made in diethylbarbituric acid buffer ( $\mu=0.1, \mathrm{pH}=8.6$ ) by the method of Longsworth (12). Determinations of lipids were carried out by the gasometric lipid carbon method of Van Slyke and Folch (13). Total and free cholesterol of the plasma was determined by the method of Schoenheimer and Sperry (14). Extraction of lipids from serum was done by freezing in the presence of ether as described by McFarlane (15). A modification of Hanger's method (7) was used for the determination of the cephalin flocculation reaction. Bromsulfalein retention was estimated by the method of Rosenthal and White (16) modified for the use of the Coleman Jr. spectrophotometer. Globulin was determined electrophoretically and by fractionation with $\mathrm{Na}_{2} \mathrm{SO}_{4}$ (17). In addition, quantitative measurements of globulin were obtained by a turbidometric technique (18).

Immunological experiments were carried out by injecting rabbits with 5 to $8 \mathrm{mgm}$. of thymol protein every 2 days for 8 injections. The antiserum was absorbed with normal human serum. Precipitin tests were carried out by the technique of Swift, Wilson, and Lancefield (19).

\section{EXPERIMENTAL}

\section{The relation of the thymol turbidity reaction to the lipids in the serum}

It was demonstrated by Maclagan (9) that the precipitate resulting from the addition of thymol reagent to serum is high in cholesterol and phospholipids. Recant, Chargaff and Hanger (20) found that sera from cases of liver disease from which lipids had been extracted with ether no longer showed turbidity following the addition of thymol reagent. These observations indicated that lipids are an important factor in the thymol turbidity reaction. This work was confirmed and extended. Thymol was found to have a special effect on lipids in general. Any lipid emulsion tended to be broken up by the addition of a thymol solution. Figure 2 shows the effect of thymol in increasing the particle size of a lipid emulsion as viewed under the microscope. When such emulsions were visualized with the naked eye, an increase in turbidity accompanied the change in particle size. This turbidity was purely the result of the physical alteration in the lipid emulsion resulting from the addition of thymol. Lipemic sera from patients with liver disease, nephrosis, diabetes, and thyroid disease all showed an increase in turbidity upon the addition of the thymol reagent. This, however, was purely a physical change in the lipid emulsion, since no protein was precipitated as in the usual thymol turbidity reaction accompanying liver disease. The following example serves to illustrate this point.

Three-tenths ml. of lipemic serum from a patient with nephrosis was diluted 60 times with the thymol barbital buffer reagent. This gave an increased turbidity over
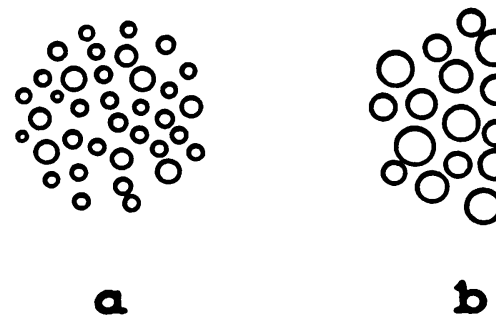

Fig. 2. Comparison of the Particle Size of Equal Quantities of a Lipid Suspension in (a) Barbital Bufrer, (b) Barbital Buffer Plus Thymol, as VIEWED UNDER THE Microscope 
the serum with barbital buffer alone equivalent to 60 units. The turbid mixture was then spun for 3 hours in the centrifuge at 15,000 r.p.m. No sediment settled at the bottom of the tube, but a white layer formed at the surface leaving a clear solution underneath. Analysis of the surface layer showed that it contained $6 \mathrm{mgm}$. total lipid and $0.001 \mathrm{mgm}$. nitrogen. The material responsible for the turbidity had been brought to the surface of the solution by high speed centrifugation and was found to contain a negligible amount of protein. A similar experiment carried out on the turbid material resulting from the addition of thymol reagent to clear serum from a case of infectious hepatitis demonstrated that the cloudy material all settled to the bottom of the tube. Nitrogen analysis of the precipitate showed that it contained 0.44 mgm. of $\mathrm{N}$. Whereas the turbidity of this serum had been found to be equivalent to only 30 units, the material responsible for the turbidity consisted of a large amount of protein.

It appears, therefore, that the turbidity produced by the action of the thymol reagent on lipemic sera from subjects without liver disease is due to an increase in the particle size of the protein-free lipid suspension, while the turbidity produced by the reagent in clear hepatitis serum is due to the formation of a protein-lipid-thymol complex.

Since certain sera from cases of liver disease are lipemic, it was of some importance to find a simple method of determining how much of the turbidity produced by the thymol reagent indicated a true reaction with precipitation of protein. When a thymol solution having the same $\mathrm{pH}$ as the usual reagent, but with a high ionic strength, was added to clear serum from a patient with liver disease giving a positive reaction, no turbidity appeared. However, when this solution was added to an artificial lipid emulsion or lipemic sera from patients with nephrosis, the turbidity produced was the same as that caused by the low ionic strength reagent. The thymol altered the state of the lipids regardless of the ionic strength of the solution. The usual protein precipitation reaction occurred only with the low ionic strength thymol reagent. In evaluating the turbidity produced in lipemic serum by Maclagan's thymol reagent, the amount of turbidity due to protein precipitation alone was obtained by using as blank in the photometer serum with the high ionic strength thymol buffer (Table I).

The presence of lipids in the serum is also an essential factor in the usual thymol turbidity reac- tion, as indicated by the fact that positively reacting sera after extraction with ether no longer give the reaction. The essential role of the lipids was further borne out by the finding that surfaceacting agents, such as various tweens, completely inhibited the formation of any precipitate in hepatitis serum to which thymol had been added. Once formed, the thymol precipitate also dissolved readily on the addition of small amounts of tween $80 .^{2}$ In other protein precipitation reactions which depended purely on the natural solubility of the proteins involved, the presence of tween actually enhanced the precipitation. The action of the tween was undoubtedly related to its effect on the state of the lipids involved in the reaction.

Since the soluble lipids play an essential part in the thymol turbidity reaction, it seemed important to test the effect of the addition of various concentrations of lipid on the reaction. Because of the specific effect of thymol on lipid suspensions it was important to keep the lipids in their most soluble state. As a result, lipid was added in the form of clear serum giving a negative thymol turbidity reaction. Four such sera were chosen containing varying amounts of lipid. When each of these sera was added to normal serum, the thymol turbidity reaction of the combination remained negative. However, when added to serum with a high gamma globulin level

TABLE I

Comparison of the turbidity in units obtained in the spectrophotometer for various sera upon the addition of the thymol reagent, using as the zero control the same sera with (a) buffer alone, (b) high ionic strength buffer with thymol

\begin{tabular}{l|c|c}
\hline \multicolumn{1}{c|}{ Type of serum } & $\begin{array}{c}\text { Buffer at } \\
\mathrm{pH} \mathrm{7.6} \mathrm{and} \\
\mu=.01\end{array}$ & $\begin{array}{c}\text { Buffer }+ \\
\text { thymol at } \\
\text { pH 7.6 and } \\
\mu=1.0\end{array}$ \\
\hline $\begin{array}{c}\text { Clear serum from patients with } \\
\text { infectious hepatitis }\end{array}$ & 26 & 26 \\
$\begin{array}{c}\text { Lipemic serum from patient with } \\
\text { nephrosis }\end{array}$ & 52 & 0 \\
$\begin{array}{c}\text { Lipemic serum from patient with } \\
\text { infectious hepatitis }\end{array}$ & 28 & 16 \\
\hline
\end{tabular}

giving a positive thymol reaction, the turbidity of the combination was proportional to the amount of lipid in the added serum. This effect was more strikingly brought out by first extracting the

\footnotetext{
2. Polyoxyethylene sorbitan monooleate.
} 
lipids from the serum of another patient with a high gamma globulin level in the serum. The thymol turbidity reaction was reduced from 22 to 9 units by this procedure. Table II shows the

TABLE II

Relative effect of the addition of $0.2 \mathrm{ml}$. of sera, differing only in their lipid content, in restoring a positive thymol turbidity reaction to $0.2 \mathrm{ml}$. ether-extracted hepatitis serum

\begin{tabular}{c|c|c|c|c}
\hline \hline $\begin{array}{c}\text { Lipid } \\
\text { content } \\
\text { of serum } \\
\text { added }\end{array}$ & $\begin{array}{c}\text { Thymol } \\
\text { turbidity } \\
\text { of serum } \\
\text { added }\end{array}$ & $\begin{array}{c}\text { Thymol } \\
\text { turbidity of } \\
\text { combination } \\
\text { of extracted } \\
\text { hepatitis serum } \\
\text { and added serum }\end{array}$ & $\begin{array}{c}\text { Protein in } \\
\text { precipitate }\end{array}$ & $\begin{array}{c}\text { Lipid in } \\
\text { precipitate }\end{array}$ \\
\hline $\begin{array}{c}\text { mgm. } \\
\text { per cent }\end{array}$ & units & units & mgm. & $m g m$. \\
500 & 3 & 14 & 1.84 & 1.11 \\
900 & 4 & 27 & 2.58 & 2.46 \\
2000 & 4 & 50 & 3.41 & 5.22 \\
\hline
\end{tabular}

relative effectiveness of various sera in restoring a positive thymol turbidity reaction to this extracted hepatitis serum. It can be seen that the high lipid sera had a much greater effect than normal serum. The major portion of the in-

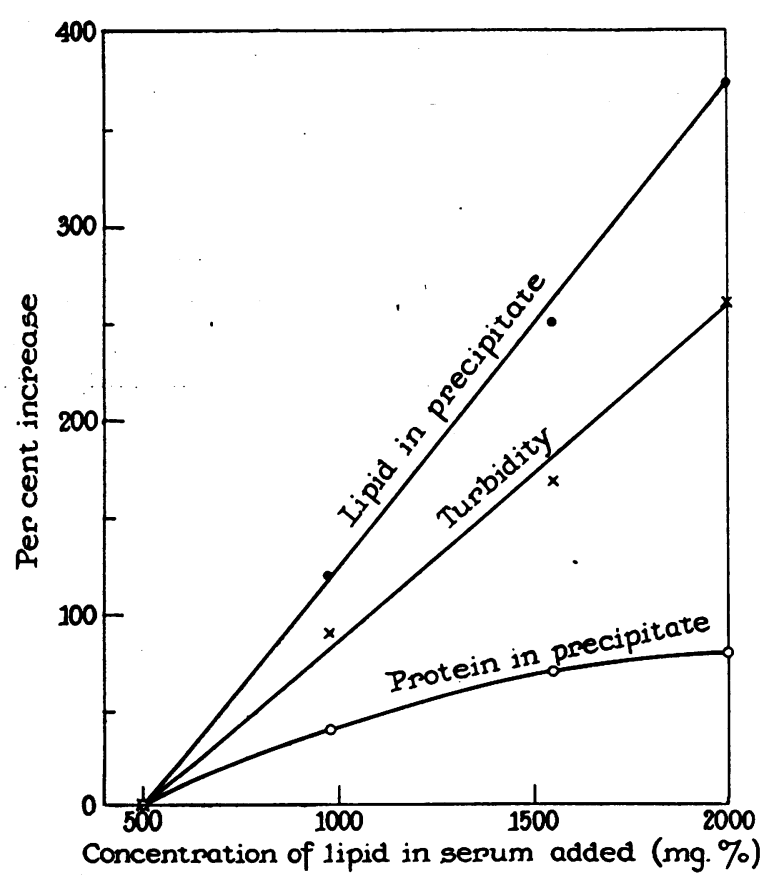

Fig. 3. Effect of the Adpition of Sera Containing Variable Amounts of Lipid on the Turbidity, Lipid Content, and Protein Content of the Precipitate. Formed in Extracted Hepatitis Serum with THYMOL REAGENT creased turbidity was due to increased precipitation of lipid as shown by the protein and lipid analyses of the precipitates. Figure 3 demonstrates more clearly the comparative effect of various lipid concentrations on the turbidity, protein content, and lipid content of the precipitate formed with extracted hepatitis serum. The results were obtained in the same experiment illustrated in Table II. It is evident that, although there is increased precipitation of protein in the presence of higher lipid concentrations, the major portion of the increased turbidity is due to increased precipitation of lipid. In other words, the resulting turbidity reflected primarily the concentration of lipid in the added serum. The relationship was so close that it was possible to use this system as a rapid method of estimating the concentration of lipid in an unknown serum.

The above data demonstrated the marked influence of lipid concentration on the thymol turbidity reaction in a somewhat artificial system involving the addition of sera with variable lipid concentrations. In order to evaluate more clearly the effect of the concentration of lipids in sera on the reaction as it is usually applied, lipid analyses were carried out simultaneously on the serum of patients with liver disease and the specific precipitate resulting from the addition of thymol reagent. The amount of lipid in the precipitate varied from 20 to 50 per cent and was directly proportional to the concentration of lipid in the original serum (Figure 4). The turbidity that is usually measured in the thymol turbidity reaction depends on both the protein and lipid that are precipitated. Since the concentration of lipid in the precipitate is proportional to the concentration in the serum, it is clear that the thymol turbidity reaction actually determines in part the concentration of lipid in the serum of patients with liver disease.

Despite the fact that the level of the lipids in the serum is one of the variables that is measured in the thymol turbidity reaction, a number of patients with liver disease other than infectious hepatitis have been observed with high lipid levels in the serum but with low or negative thymol turbidity test values. Fractionation of the total lipid in these cases into the cholesterol and phospholipid partitions did not reveal any specific effect. The addition of reactive protein, or serum contain- 


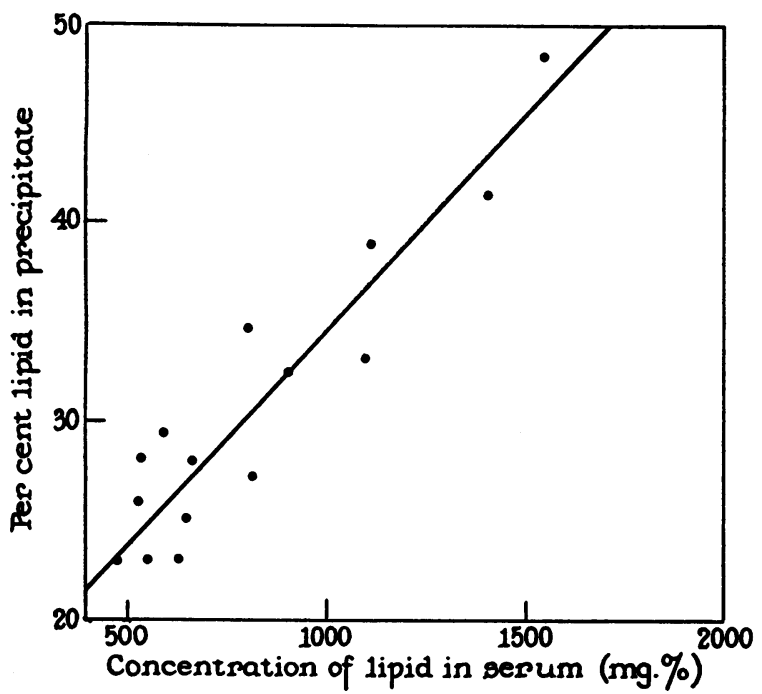

Fig. 4. The Relation of the Lipid Content of Serum from Patients with Liver Disease to the Lipid Content of the Specific Precipitate Formed In the Thymol Turbidity Reaction

ing reactive protein, always produced a positive reaction in proportion to the total lipid concentration. The presence of the thymol-reacting protein was the essential factor while the level of the lipids affected only the intensity of the reaction.

\section{Identification of the protein involved in the thymol turbidity reaction}

Maclagan (9) analyzed the precipitate obtained in a positive thymol turbidity reaction and found that it consisted of approximately 40 per cent protein. He suggested that this was probably a gamma globulin because of its low solubility. Hanger and associates (20) were unable to obtain positive thymol turbidity reactions by adding gamma globulin electrophoretically separated from hepatitis sera to normal sera and various lipid fractions. They concluded that the protein involved in the reaction was probably an alpha or beta globulin and not in the gamma globulin fraction.

(a) Electrophoretic analysis of the thymol precipitate. Studies of the precipitate obtained with thymol reagent were hampered by the large amount of lipid that was present. Turbid solutions were always obtained when attempts were made to dissolve the precipitate and it was impossible to obtain an electrophoretic pattern. Extraction of

the lipids from the precipitate in the cold with ether alone, ether and alcohol, or acetone alone, always resulted in denaturation of the proteins in the precipitate. When removed from serum the proteins were apparently less resistant to the action of organic solvents.

Attempts were also made to dissolve the precipitate resulting from the thymol reaction in normal serum and observe the change in the electrophoretic pattern. The high lipid concentration, however, still interfered and no conclusive results could be obtained. The difficulty was finally overcome by the use of tween 80 , a strong emulsifying agent. A 1 per cent concentration of this material did not affect the electrophoretic pattern of normal serum. A clear solution suitable for electrophoretic determinations was obtained in the following manner.

Two hundred ten ml. of thymol reagent were added to $15 \mathrm{ml}$. of very reactive hepatitis serum (38 units) at $0^{\circ} \mathrm{C}$. The precipitate was collected by centrifugation in the cold and suspended in $10 \mathrm{ml}$. barbital buffer containing 1 per cent tween at $\mathrm{pH} 8.5$ and $\mu=0.1$. This was then dialyzed in the cold against barbital buffer at the same $\mathrm{pH}$ and ionic strength. A small amount of sediment that still remained was thrown down by centrifugation and the resulting supernate was quite clear.

Figure 5 shows the electrophoretic pattern of the protein solution obtained in the above manner. The sharp peak $(b)$, representing almost the entire amount of protein present, had a mobility of $1.6 \times 10^{-5}$ which places it in the gamma globulin fraction but with an unusually rapid mobility. A

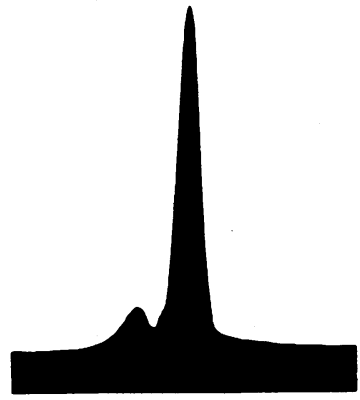

(a) (b)

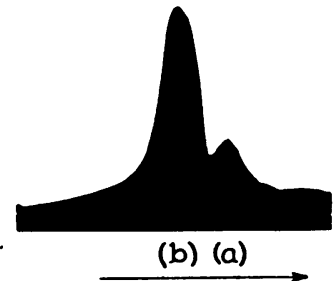

Fig. 5. Ascending and Descending Electrophoretic Patterns of the Protein Component of the Precipitate Formed in the Thymol Turbidity Reaction

Peak $(a)=\beta$ globulin $\left(\mu=2.83 \times 10^{-5}\right)$; peak $(b)$ $=\gamma$ globulin $\left(\mu=1.60 \times 10^{-5}\right)$. 
small definite beta globulin peak $(a)$ is also visible. In a second experiment with material from another patient, lipid and tween were removed by subjecting the protein to repeated precipitations from large volumes of solution by lowering the salt concentration. The final preparation contained no lipid and the electrophoretic pattern showed a single peak with the mobility of a gamma globulin. Further experiments with the thymol-precipitated protein in the absence of tween indicated that when all of the lipid was removed by centrifugation at 12,000 r.p.m. at high salt concentrations, the remaining protein migrated extremely slowly. In 1 experiment the mobility was $0.5 \times 10^{-5}$. It appeared as if the more lipid that was removed, the more slowly the remaining protein migrated.

(b) Effect of the addition of gamma globulin to normal serum. The importance of the gamma globulin fraction was borne out in a series of experiments with gamma globulin separated electrophoretically from various types of sera. Considerable difficulty was encountered in adjusting the protein concentration, the ionic strength, and the $\mathrm{pH}$ of each fraction to exactly the same level because of the small and variable amount of gamma globulin that was obtained by electrophoretic separation. Slight variation in these fractions caused marked differences in their effect on the thymol turbidity reaction of serum and, as a result, this method of studying the protein component responsible for the reaction was not completely satisfactory. However, it was possible to demonstrate that gamma globulin fractions from certain sera demonstrating a very high thymol turbidity reaction, although negative alone, produced positive reactions with thymol reagent when added to normal serum. The gamma globulin precipitated with thymol reagent only in the presence of lipid. The amount of turbidity produced was proportional to the concentration of lipid in the serum to which the gamma globulin was added. No turbidity was produced with serum in the presence of a small amount of tween.

That the gamma globulin fraction is important in the thymol reaction as it is usually carried out was also indicated by experiments where this fraction was removed from 2 positive sera electrophoretically. The sera, after being brought to their previous state in all respects, except that the gamma globulin was absent, now gave a negative reaction.

Comparison of gamma globulin preparations from various sera in respect to their ability to induce a positive reaction in the presence of lipid was attempted (Table III). Four mgm. of

TABLE III

Comparative effect of equal concentrations of gamma globulin, obtained from various sources, on the thymol turbidity reaction of a high lipid serum

\begin{tabular}{l|c|c}
\hline \hline \multicolumn{1}{c|}{$\begin{array}{c}\text { Source of gamma } \\
\text { globulin }\end{array}$} & $\begin{array}{c}\text { Thymol } \\
\text { turbidity } \\
\text { of serum }\end{array}$ & $\begin{array}{c}\text { Thymol turbidity } \\
\text { of gamma globulin } \\
\text { on addition of } \\
\text { serum containing } \\
\text { 950 mgm. } \\
\text { per cent lipid }\end{array}$ \\
\hline 1. Hepatitis serum & units & units \\
2. Hepatitis serum & 40 & 26 \\
3. Normal serum & 31 & 28 \\
4. Normal serum & 3 & 16 \\
5. Cirrhosis serum & 2 & 20 \\
6. Multiple myeloma serum & 4 & 21 \\
\hline
\end{tabular}

gamma globulin were added to each $0.1 \mathrm{ml}$. of serum used. The gamma globulin obtained from the serum showing the pattern illustrated in Figure $6 a$ was slightly more active in inducing a positive thymol reaction than was that obtained from normal serum. It also appeared to be slightly more active than was gamma globulin obtained from the serum of a patient with cirrhosis of the liver which showed an increase in the gamma globulin fraction but a negative thymol turbidity reaction. A definite and clear-cut difference in activity was obtained when the hepatitis gamma globulin was compared with gamma globulin from the serum of a patient with multiple myeloma. The latter serum had given a negative thymol turbidity reaction. Since all the gamma globulin preparations had some activity in the presence of lipid, it was impossible to draw very definite conclusions. Certainly, the activity of the gamma globulin preparations was not proportional to the activity of the sera from which they were obtained.

(c) The change in the electrophoretic pattern of hepatitis serum following removal of the thymol protein. In order to obtain further information about the protein or protein complex that is precipitated with thymol reagent, electrophoretic analyses were carried out on 3 highly active hepatitis sera before and after removal of the thymol 

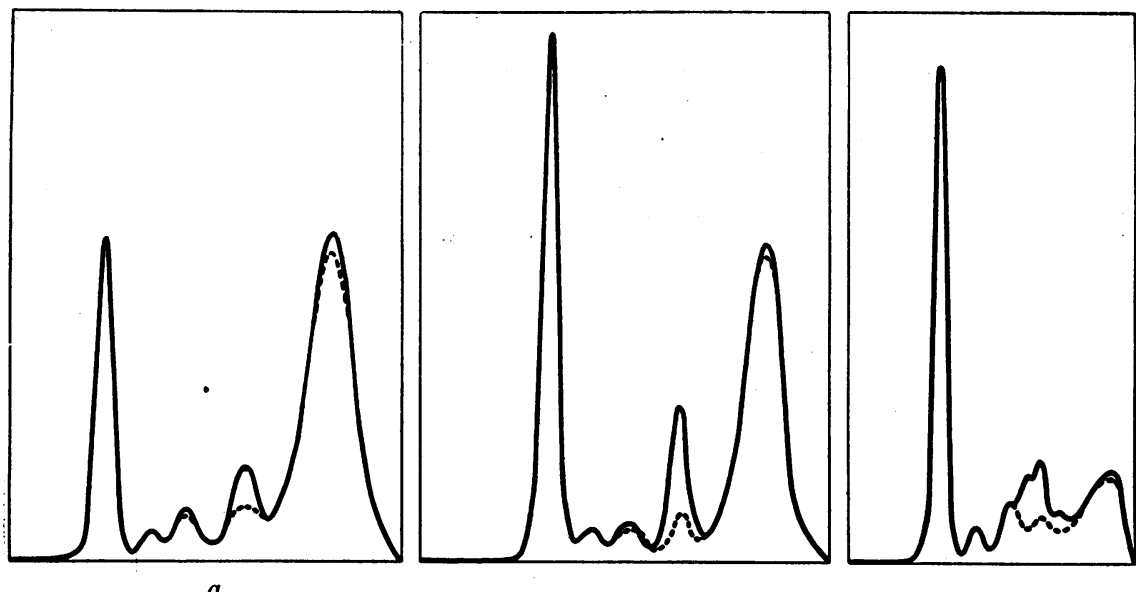

Fig. 6. Ascending Electrophoretic Patterns before and after Removal of the Thymol Prectpitate in 3 Patients Demonstrating Very High Values for THE Thymol Turbidity Test

The dotted lines indicate the areas which were altered by the precipitation.

precipitate. The thymol precipitate-free serum was obtained in the following manner.

To $7 \mathrm{ml}$. of hepatitis serum, $98 \mathrm{ml}$. of thymol reagent were added. The precipitate was permitted to settle for 30 minutes and then removed by centrifugation. The clear supernatant solution was dialyzed against saline until all traces of thymol were removed. The volume of solution was brought down by evaporation in the dialysis bag placed in front of an electric fan. This procedure was continued until the protein content of the solution was equal to that in the original serum minus the quantity in the thymol precipitate. Electrophoretic analyses were then carried out after the usual adjustment to a $\mathrm{pH}$ of 8.6 and $\mu=0.1$ by dialysis against barbital buffer.

By superimposing the tracings obtained before and after removal of the thymol precipitate (Figure 6), the differences in the electrophoretic patterns of the 3 sera are clearly visible. The predominant alteration was in the beta globulin fraction. The question arises as to whether the change in this fraction is due solely to the removal of lipid from the serum as a result of the thymol precipitation. A decrease in the beta globulin is known to occur with extraction of lipids from the serum by means of organic solvents. Calculation by planimetry of the protein lost from the gamma globulin peak showed some variation in the ascending and descending patterns of the same serum. In addition, the amount of protein lost by the precipitation was small in comparison with the total protein, less than 8 per cent in all 3 cases. It was, therefore, difficult to obtain exact evidence as to how much of the protein precipitated came from the gamma globulin fraction. The figures obtained ranged between 25 and 45 per cent with an average of 37 per cent for the ascending and descending patterns of the 3 sera. These results indicated a portion of the precipitated protein came from the gamma globulin fraction but that the largest portion came from the beta fraction.

(d) Immunological results. In order to find out more definitely whether the globulin precipitated in the thymol turbidity reaction is an abnormal protein or just an increased amount of normal protein in the serum, antibodies to the protein illustrated in Figure 5 were obtained in rabbits. The antiserum reacted strongly with normal serum, and no definite difference could be obtained with sera containing large amounts of gamma globulin or sera giving a very positive thymol turbidity reaction. Absorption of the antiserum with normal serum did not aid in demonstrating a difference between normal and hepatitis serum.

(e) Effect of albumin on the thymol turbidity reaction. In view of the known effect of albumin in increasing the solubility of proteins in general and the specific effect of albumin on the cephalin flocculation reaction (8), studies were carried out to determine its effect on the thymol turbidity reaction. Figure 7 demonstrates the fall in the values 
for the thymol turbidity test in the serum of a patient with hepatitis upon the addition of increasing amounts of concentrated human albumin. The albumin concentration of the serum had to be almost doubled before much change occurred.

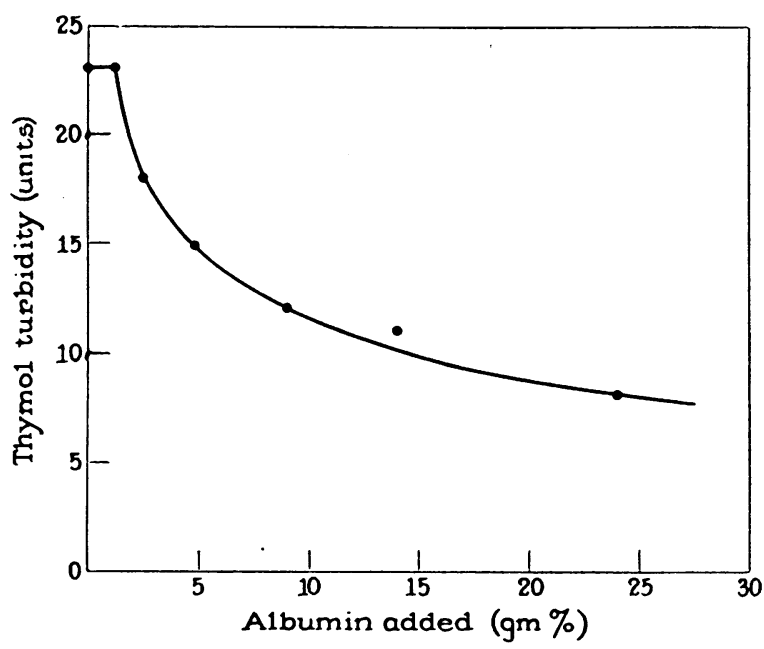

Fig. 7. The Effect of the Addition of Various Amounts of Human Albumin on the Thymol Turbidity Reaction in the Serum of a Patient with INFECTIOUS HEPATITIS

In vivo studies with concentrated solutions of human serum albumin in patients with diseases of the liver have shown a definite decrease in the intensity of the thymol turbidity reaction of the serum following intensive therapy with this material. The decrease in the thymol turbidity reaction could be accounted for partly on the basis of an increase in plasma volume and on the in vitro effect of albumin described in the previous paragraph. However, in certain patients the fall was too great to be explained in such a manner. An example of such an effect was seen in the case of a 12-year-old boy with very severe acute infectious hepatitis accompanied by edema and ascites. The administration of three 25 -gram units of albumin produced a fall in the thymol turbidity reaction from 27 to 7 units with an increase of only 1 gram per cent in the serum albumin level. The change in plasma volume in this patient was approximately 10 per cent. The cephalin flocculation reaction showed no change during this period. The thymol turbidity reaction returned to its original level within 6 days following cessation of therapy. Apparently, in the body, albumin may have a specific effect on the reaction not encountered in the in vitro experiment. The level of albumin in the body, therefore, is another factor influencing the intensity of the thymol turbidity reaction.

III. Clinical observations on the effect of the protein and lipid components of the serum on the thymol turbidity reaction during the course of acute infectious hepatitis.

In order to demonstrate further the influence of the lipid level of the serum on the reaction under study, lipid determinations were carried out on

TABLE IV

Average lipid concentration in the serum of patients with acute infectious hepatitis showing high thymol turbidity test values compared with those showing low values

\begin{tabular}{c|c|c|c}
\hline \hline Group & $\begin{array}{c}\text { No. of } \\
\text { patients }\end{array}$ & $\begin{array}{c}\text { Thymol } \\
\text { turbidity } \\
\text { test values }\end{array}$ & $\begin{array}{c}\text { Average } \\
\text { total lipid } \\
\text { concentration }\end{array}$ \\
\hline A & 6 & above 25 & 1275 \\
B & 6 & below 15 & 610 \\
\hline
\end{tabular}

2 groups of patients during the early icteric phase of acute infectious hepatitis (Table IV). The

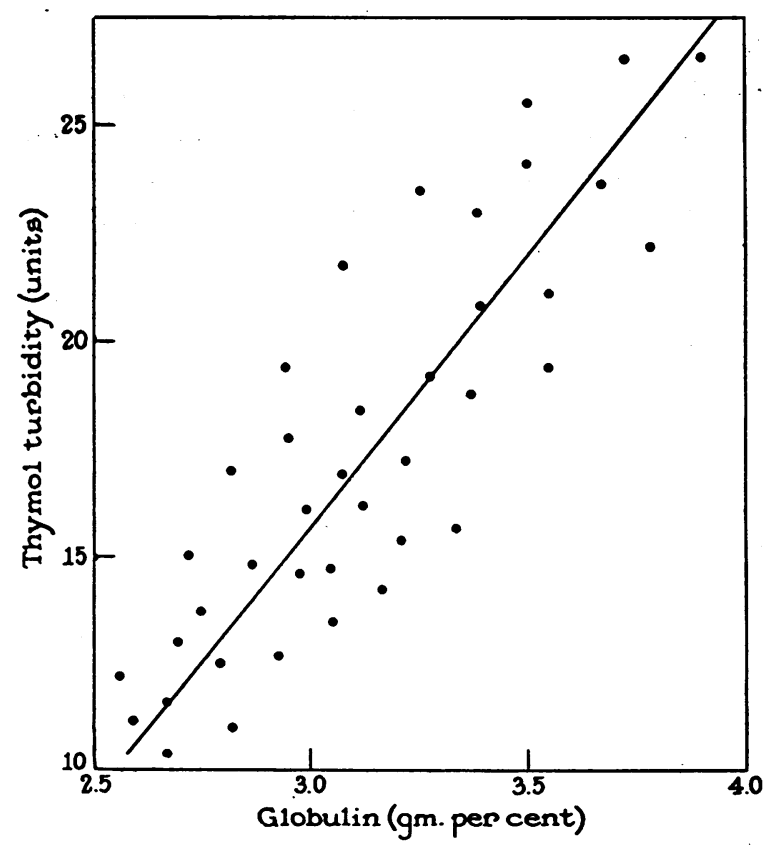

Fig. 8. Relation between the Elevation of the Thymol Turbidity Test and the Globulin LeVel of the Serum during the Convalescent Period of Acute INFECTIOUS HEPATITIS 


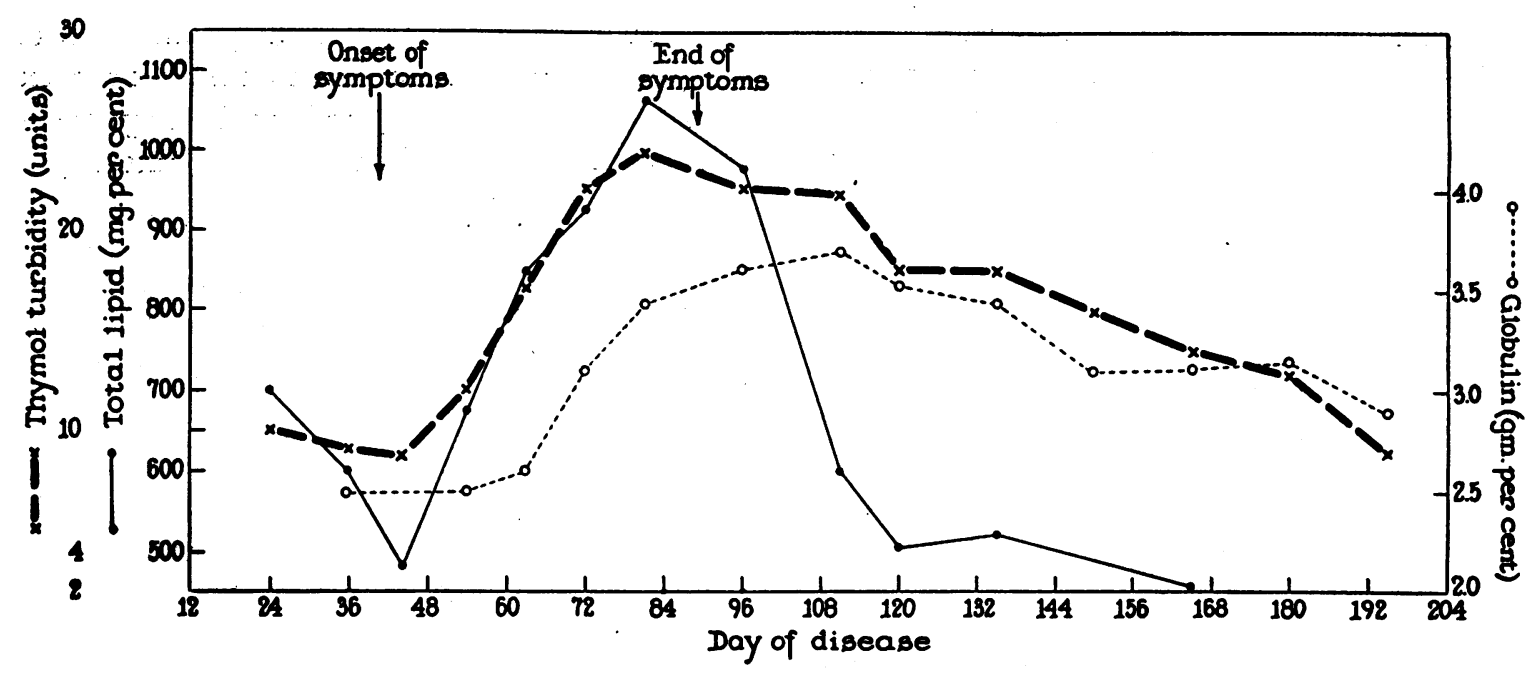

Fig. 9. Illustration of the Close Parallelism between Thymol Turbidity and Lipid Determinations Initially, and between Thymol Turbidity and Total Globulin Determinations during the Later Period in a Relapse of Infectious Hepatitis

severity of the illness in the 2 groups was approximately equal and they differed only in the intensity of the thymol turbidity reaction. None of the patients showed more than slight elevation of the globulin level. It can be seen that the average lipid concentration in the sera of patients with high values for the thymol turbidity test was much greater than in the group showing low values.

During the convalescent period of infectious hepatitis the influence of the lipid level became less pronounced and values for the thymol turbidity test paralleled the globulin level of the serum to a close degree. Figure 8 demonstrates this relation in a group of patients during convalescence at a time when the lipid changes were minimal.

The comparative influence of the protein and lipid components on the thymol turbidity reaction during the course of infectious hepatitis may also be seen from Figure 9. This chart illustrates the close parallelism of values obtained by simultaneous determinations of the thymol turbidity reaction and plasma lipids in demonstrating a delayed rise during the course of a recurrence of acute infectious hepatitis. The total globulin level showed an even more delayed elevation and during the late convalescent period the thymol turbidity reaction followed the pattern of the globulins very closely. Electrophoretic determinations demonstrated that the rise in total globulin was al- most entirely due to an increase in the gamma globulin fraction.

\section{DISCUSSION}

The experiments that have been described make it clear that there are 2 main components in serum that are important in the thymol turbidity reaction: (a) the protein component, (b) the lipid component. Electrophoretic analyses have indicated that these 2 components are not separate but are intimately related. The entire question revolves about the difficult problem of loose proteinlipid combinations that migrate in the beta globulin fraction of serum. The ease with which these combinations are broken makes it difficult to study the lipid-protein complexes individually. The observations reported have shown a slower electrophoretic migration of the protein as the lipid is removed and suggest the possibility that some beta globulins may represent light combinations of lipid and gamma globulin.

In view of the specific effect of thymol on lipids in general, it seems logical to suppose that dilution of serum with a thymol solution would tend to throw lipid-protein complexes out of solution. The protein is carried along by the effect of thymol in decreasing the solubility of the lipids. In addition, the low ionic strength buffer used in the reagent will sometimes precipitate gamma globulin 
from hepatitis serum (18) in the absence of thymol. Such a buffer solution has been used by Wolff for detecting the globulin elevation in malaria serum (21). The effect of the thymol in increasing the precipitate appears to be attributable to the action of thymol in decreasing the emulsification of lipids. The inhibitory effect of emulsifying agents on the thymol turbidity reaction also indicated that the protein precipitation was enhanced by the effect of thymol on the lipids in the serum. The reaction, therefore, probably results from a combination of the effect of thymol in decreasing the dispersion of the lipid component, and the effect of dilution with low ionic-strength buffer in decreasing the solubility of the globulin component, in such a way as to precipitate the protein-lipid combination.

The fact that the lipids of the serum play a greater role in the thymol turbidity reaction than just forming a part of the protein-lipid-beta globulin complex essential to the reaction, is indicated by the observations which demonstrated that the per cent lipid in the thymol precipitate is proportional to the total lipid in the serum of patients with infectious hepatitis. In addition, the experiments with mixtures of 2 different sera showed that a high lipid serum, although negative by itself, markedly affected the intensity of the reaction of the combination.

The effect of gamma globulin in acting with normal serum to give a positive thymol turbidity reaction suggests a similarity to the cephalin flocculation reaction where such an effect is also seen (8). One of the main points of dissimilarity between the 2 reactions that has been cited (20) is that extraction of the lipids from hepatitis serum does not affect the cephalin flocculation reaction as it does the thymol reaction. This, however, cannot be considered a fundamental difference because, in the cephalin flocculation reaction, the cephalin-cholesterol reagent used supplies ample lipid to an extracted serum. The thymol alters the state of the lipids of the serum so that a lipid globulin complex precipitates from the serum of certain patients with liver involvement. In the cephalin flocculation reaction, a lipid suspension is added to the serum so that a lipid globulin complex precipitates. The difference in the 2 tests is mainly in the manner in which the lipid globulin precipitation is brought about. Clinically, the 2 tests are related, although occasional marked differences do occur $(11,22$ to 24$)$. One of the main discrepancies is seen in the earlier development of a positive cephalin flocculation reaction during the pre-icteric stage of acute infectious hepatitis. A possible explanation may lie in the fact that the lipids show a delayed rise in this disease, and, therefore, the effect of increased lipids on the thymol reaction would not be present.

An increased concentration of gamma globulin was found electrophoretically in all sera showing a positive thymol turbidity reaction. Most of the positive sera but not all also showed increased amounts of beta globulin. There is difficulty in explaining negative reactions in certain patients with cirrhosis of the liver who have markedly increased gamma globulin levels, high beta globulin concentrations, high total lipid values and, in addition, low plasma albumin. This should be the ideal situation for a very positive thymol turbidity reaction. The evidence for a qualitative difference in the increased globulin is not sufficiently conclusive to explain such a case entirely, especially in view of the negative results obtained in immunization experiments. Similar discrepancies have been noted in the cephalin flocculation reaction and Hanger and his associates (8) have obtained evidence that albumin plays an important role. This problem requires further study.

In the course of studies on patients with various types of liver disease associated with marked hypergammaglobulinemia, it was noted that most of them had equally high thymol turbidity values: approximately 35 units. This was also true of sera from patients with kala azar and schistosomiasis with marked hypergammaglobulinemia. This represented a protein precipitation of approximately 0.8 gram, a very small portion of the gamma globulin of these sera. This was not true of patients with multiple myeloma. The gamma globulin elevation in this disease appears to be very different. A negative thymol turbidity reaction was always obtained. It appeared as if there was a maximal amount of protein that could be precipitated. A possible explanation for this phenomenon may reside in the fact that all these sera showed approximately the same amount of lipid and, therefore, only a limited amount of lipid was 
available to precipitate with globulin in the presence of thymol reagent. More.protein readily precipitated if additional lipid was added.

The close relation between the level of the lipids in serum and the intensity of the thymol turbidity reaction must be kept in mind in evaluating observations by this test because of the frequent occurrence of elevation of the plasma lipids in liver disease. The dependence of the test on 2 variable factors, the protein and lipid components, is somewhat of a disadvantage to a clear analysis of the significance of the reaction. This may be the reason for the lack of correlation between the intensity of the reaction and the severity of illness observed in a clinical study of infectious hepatitis (22).

Serial determinations of the thymol turbidity test during the course of infectious hepatitis have revealed that values for the test show a delayed rise following the onset of the disease and a prolonged elevation during convalescence (25). The relative effect of the lipid and globulin components of the reaction upon this pattern was demonstrated. The values for the thymol turbidity test closely paralleled the plasma lipids during the acute phase of the disease and the total globulin level during convalescence. The prolonged high values for the thymol turbidity test following infectious hepatitis were due to persistent elevation of the serum globulins. These observations were substantiated by electrophoretic patterns taken during the course of this disease. During the early period of elevation of values for the thymol turbidity test the dominant abnormality was an increase in the electrophoretic beta globulin. This was a reflection of the elevated plasma lipids. Later the predominant aberration was an increase in the gamma globulin, which remained elevated as long as the thymol turbidity reaction remained positive. Thus, it is apparent that the thymol turbidity test has a different significance during different stages of a single disease such as acute infectious hepatitis.

Determination of the lipid changes alone is not a sensitive index of acute liver damage, and there is no simple specific method of determining the small increases in globulin following such damage. The thymol turbidity test in reflecting the combination of these aberrations is a more sensitive index of liver injury than either one alone. Since the essential factor in the mechanism of the reaction is the increase in the globulin component following acute liver injury, investigations of the significance of the reaction really call for an understanding of the corresponding hyperglobulinemia.

The serum globulins are known to show a delayed rise in several diseases; this has been considered to be a reflection of the development of antibodies. Recent studies on typhus (26), however, have demonstrated that complement fixation tests and the Weil-Felix reaction did not parallel the alteration in globulin. The explanation for the change in liver disease is also very obscure. Liver biopsies obtained from the patients with marked hyperglobulinemia have revealed marked evidence of regeneration of liver tissue, suggesting that globulin elevation may be correlated with the healing process.

\section{SUMMARY}

1. The turbidity produced by the thymol reagent of Maclagan in the serum of patients with infectious hepatitis is shown to depend on the presence both of lipids and of abnormal lipid protein complexes migrating in the beta globulin fraction of the serum. The gamma globulin fraction of serum also plays an important role in the reaction. The relative importance of the different components in the reaction varies with different sera. Development of the turbidity is prevented if the lipids are kept in solution by the addition of a tween or are extracted with ether, or if the gamma globulin is removed.

2. In lipemic sera the thymol reagent causes a nonspecific increase in the turbidity due to increase in particle size of the lipid globules. Correction for this effect can be made by using a photometric blank prepared from serum and a thymol reagent containing such a high buffer concentration that precipitation of the globulin component is prevented.

3. Immunological studies did not reveal evidence that the protein concerned in the reaction was abnormal.

4. A possible similarity between the mechanism of the thymol turbidity and cephalin flocculation reactions was discussed. 
5. In patients with acute infectious hepatitis values for the thymol turbidity test were found to parallel alterations in serum lipids initially and alterations in gamma globulin during late convalescence.

\section{BIBLIOGRAPHY}

1. Filinski, W., L'Augmentation de taux de la globuline dans le sérum du sang comme résultat de l'insuffisance hépatique. Presse Méd., 1922, 30, 236.

2. Wiener, H. J., and Wiener, R. E., Plasma proteins. Arch. Int. Med., 1930, 46, 236.

3. Foley, E. F., Keeton, R. W., Kendrick, A. B., and Darling, D., Alterations of serum protein as an index of hepatic failure. Arch. Int. Med., 1937, 60,64 .

4. Cassiano P., Applicazioni della reazione di Takata in psichiatria. Schizofrenie, 1935, 4, 151.

5. Magath, J. B., The Takata-Ara test of liver function. Proc. Staff Meet., Mayo Clin., 1935, 10, 493.

6. Levinson, S. A., Klein, R. I., and Rosenblum, P., The Weltmann serum coagulation reaction; Preliminary report. J. Lab. \& Clin. Med., 1937, 23, 53.

7. Kabat, E. A., Hanger, F. M., Moore, D. H., and Landow, $\mathrm{H}$., The relation of cephalin flocculation and colloidal gold reactions to the serum proteins. J. Clin. Invest., 1943, 22, 563.

8. Moore, D. B., Pierson, P. S., Hanger, F. M., and Moore, D. H., Mechanism of the positive cephalincholesterol flocculation reaction in hepatitis. $\mathrm{J}$. Clin. Invest., 1945, 24, 292.

9. Maclagan, N. F., The thymol turbidity test as an indicator of liver dysfunction. Brit. J. Exper. Path., 1944, 25, 234.

10. Shank, R. E., and Hoagland, C. L., A modified method for the quantitative determination of thymol turbidity reaction of serum. J. Biol. Chem., 1946, $162,133$.

11. Neefe, J. R., Results of hepatic tests in chronic hepatitis without jaundice; correlation with the clinical course and liver biopsy findings. Gastroenterology, 1946, 7, 1.

12. Longsworth, L. G., Recent advances in the study of proteins by electrophoresis. Chem. Rev., 1942, $30,323$.

13. Van Slyke, D. D., and Folch, J., Manometric carbon determination. J. Biol. Chem., 1940, 136, 509.

14. Schoenheimer, R., and Sperry, W .M., A micromethod for the determination of free and combined cholesterol. J. Biol. Chem., 1934, 106, 745.

15. McFarlane, A. S., Behavior of the lipoids in human serum. Nature, 1942, 149, 439.

16. Rosenthal, S. M., and White, E. C., Clinical application of the bromsulphalein test for hepatic function. J. A. M. A., 1925, 84, 1112.

17. Howe, P. E., The use of sodium sulfate as the globulin precipitant in the determination of proteins in blood. J. Biol. Chem., 1921, 49, 93.

18. Kunkel, H. G., The use of a serum dilution technique for the rapid and quantitative estimation of elevated globulin with special reference to liver disease. To be published.

19. Swift, H. F., Wilson, A. T., and Lancefield, R. C., Typing group A hemolytic streptococci by $M$ precipitin reactions in capillary pipettes. J. Exper. Med., 1943, 78, 127.

20. Recant, L., Chargaff, E., and Hanger, F., Comparison of the cephalin-cholesterol flocculation with the thymol turbidity test. Proc. Soc. Exper. Biol. and Med., 1945, 60, 245.

21. Wolff, E. K., Buffer precipitation test (B.P.T.) for malaria. Tr. Roy. Soc. Trop. Med. \& Hyg., 1939, $32,707$.

22. Kunkel, H. G., Value and limitations of the thymol turbidity test as an index of liver disease. Am. J. Med., In Press.

23. Havens, W. Paul, Jr., and Marck, R. E., A comparison of the cephalin-cholesterol flocculation and thymol turbidity tests in patients with experimentally induced infectious hepatitis. J. Clin. Invest., 1946, 25, 816.

24. Watson, C. J., and Rappaport, E. M., A comparison of the results obtained with Hanger cephalincholesterol flocculation test and the Maclagan thymol turbidity test in patients with liver disease. J. Lab. and Clin. Med., 1945, 30, 983.

25. Kunkel, H. G., and Hoagland, C. L., Persistence of elevated values for the thymol turbidity test following infectious hepatitis. Proc. Soc. Exper. Biol. and Med., 1946, 62, 258.

26. Tierney, N. A., and Yeomans, A., Metabolic studies in louse-borne typhus. Observations on serum electrolyte pattern, serum protein partition, and nitrogen balance. J. Clin. Invest., 1946, 25, 822.

\section{ACKNOWLEDGMENT}

The authors are indebted to Dr. T. Shedlovsky and Dr. D. A. MacInnes for their generosity in making available the electrophoretic equipment used in this study. 